\title{
The autoxidation activity of new mixed-ligand manganese and iron complexes with tripodal ligands
}

\author{
Remy van Gorkum ${ }^{\mathrm{a}}$, Joris Berding a ${ }^{\mathrm{a}}$, Duncan M. Tooke ${ }^{\mathrm{b}}$, Anthony L. Spek ${ }^{\mathrm{b}}$, Jan Reedijk ${ }^{\mathrm{a}}$, \\ Elisabeth Bouwman ${ }^{\mathrm{a}, *}$ \\ ${ }^{a}$ Leiden Institute of Chemistry, Gorlaeus Laboratories, Leiden University, PO Box 9502, 2300 RA Leiden, The Netherlands \\ b Bijvoet Center for Biomolecular Research, Crystal and Structural Chemistry, Utrecht University, 3584 CH Utrecht, The Netherlands
}

Received 13 July 2007; revised 13 September 2007; accepted 13 September 2007

\begin{abstract}
The activity of new manganese and iron complexes of dianionic tripodal ligands in the autoxidation of ethyl linoleate (EL) is reported. EL consumption rates were monitored using time-resolved FTIR and the degree of oligomerisation was determined by SEC. Almost all complexes showed the same trend in the autoxidation of EL. After a short induction time, the reaction started at a relatively high constant rate; later, this rate changes to a lower rate, which was again constant and on average was the same for all complexes studied. The observation that the autoxidation rate eventually became the same for all complexes can be explained with the assumption that a catalytic species was formed that was structurally similar for each complex. The crystal structure of a representative new complex, [Mn(papy)(acac)] $\left(\mathrm{H}_{2}\right.$ papy $=N$-(2-hydroxybenzyl)- $N$-(2-picolyl)-glycine; Hacac $=$ acetylacetone $)$, was elucidated, demonstrating a Jahn-Teller distorted octahedral geometry of the Mn(III) ion. To gain insight into the reaction mechanisms by which these manganese complexes react with peroxides, the reaction of $[\mathrm{Mn}(\mathrm{pppy})(\mathrm{dpm})]$ with alkyl hydroperoxides was studied using UV-vis and EPR spectroscopy $\left(\mathrm{H}_{2}\right.$ pppy $=2$-[bis(2-hydroxybenzyl)aminomethyl]-pyridine; Hdpm = dipivaloylmethane). It is proposed that in a reaction of $[\mathrm{Mn}(\mathrm{pppy})(\mathrm{dpm})]$ with $t$-butyl hydroperoxide $\left({ }^{t} \mathrm{BuOOH}\right)$, the species $\left[\mathrm{Mn}(\mathrm{III})(\mathrm{pppy})(\mathrm{OH})\left({ }^{t} \mathrm{BuOO} \cdot\right)\right]$ is formed. In analogy with the formation of that species, which is postulated to occur through a reduction to $\mathrm{Mn}$ (II), it is proposed that in the direct initiation reaction of EL with a manganese(III) complex, a 1 electron-1 proton transfer reaction leads to the formation of Mn(II) and an EL radical. Considering parameters such as autoxidation activity, complex solubility and ease of complex preparation, the compound [Mn(III)(tbpppy)(dpm)] $\left(\mathrm{H}_{2}\right.$ tbpppy $=2$-[bis(2-hydroxy-3,5-di-tert-butylbenzyl) aminomethyl]pyridine) is expected to be the best potential alkyd paint drier.
\end{abstract}

(c) 2007 Elsevier Inc. All rights reserved.

Keywords: Ethyl linoleate; Manganese complexes; Tripodal ligands; Autoxidation; Catalysts

\section{Introduction}

Cobalt complexes are the most widely used drying catalysts for oxidative air-drying of alkyd paints. However, several reports have been published describing the possible carcinogenicity of cobalt salts and cobalt complexes $[1,2]$. Some commercial paint formulations contain manganese carboxylate as a primary drier, even though these do not have the same performance as cobalt-based driers [3,4]. This has initiated a search to find alternatives for cobalt complexes as drying catalysts in alkyd paint [5-10]. Recently, our group reported on

\footnotetext{
* Corresponding author.

E-mail address: bouwman@chem.leidenuniv.nl (E. Bouwman).
}

the manganese-based catalyst system $\left[\mathrm{Mn}(\mathrm{acac})_{3}\right] / \mathrm{bpy}$ (bpy $=$ $2,2^{\prime}$-bipyridine), which exhibited very high activity in the oxidation of unsaturated fatty acids [8,11]. Unfortunately, $\left[\mathrm{Mn}(\mathrm{acac})_{3}\right]$ is dark-coloured, precluding its application in many commercial paint products. Nevertheless, this research result stimulated further research to find new manganese-based drying catalyst systems.

Lipoxygenases are manganese or iron-containing dioxygenases that act on lipid substrates containing one or more $(Z, Z)-1,4$-pentadiene moieties [12]; they are widely distributed among plants and animals. Common polyunsaturated fatty acids, such as linoleic, linolenic, and arachidonic acids, are the natural substrates for these enzymes; the primary reaction products are hydroperoxides of conjugated $(E, Z)$-dienes. In fact, 

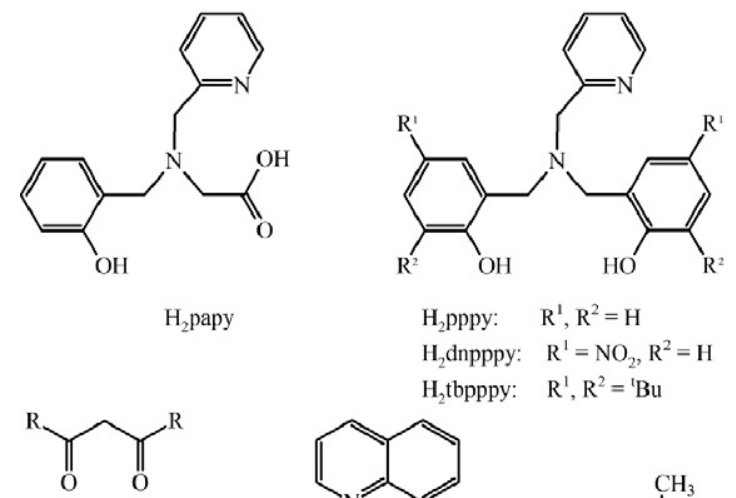

Hacac: $\mathrm{R}=\mathrm{CH}_{3}$ Hdbm: $\quad \mathrm{R}=\mathrm{C}_{5} \mathrm{H}_{6}$ Hdpm: $\quad \mathrm{R}={ }^{\mathrm{t}} \mathrm{Bu}$

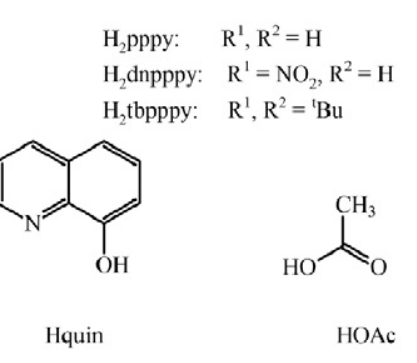

Scheme 1. Ligands used in this study.

model complexes for the lipoxygenase active site could very well be good catalytic driers for alkyd paints, especially if they also would be able to catalytically decompose hydroperoxides. Tripodal ligands with phenol groups have been used extensively in the synthesis of iron and manganese complexes to model the active sites of various dioxygenase and phosphatase enzymes [13-17].

The impetus for the use of tripodal ligands in the search for paint-drying catalysts is that such tetradentate ligands usually form relatively stable complexes with manganese and iron. The formed complexes are expected to be robust and thus are not readily decomposed under oxidising conditions. This last point is especially important, because these complexes must act as radical autoxidation catalysts and are subject to oxidising conditions. An additional benefit of this ligand type is that the synthesis of the ligands is straightforward and variations on the ligand structure are readily possible. $\beta$-Diketonates were chosen as the "secondary" ligand because good autoxidation results have been obtained with simple, homoleptic manganese $\beta$-diketonate complexes [7,8]. We have synthesised and characterised a series of manganese(III) and iron(III) coordination compounds with one dianionic tripodal ligand and one auxiliary ligand (Schemes 1 and 2) [18]. The resulting complexes are noncharged, which is expected to result in good solubility in apolar solvents. A good solubility in the apolar paint medium is considered to be one of the most crucial properties of potential paint driers [19].

Herein, we report the autoxidation activity of the complexes in a model reaction with ethyl linoleate; the different activities are compared using time-resolved FT-IR and size-exclusion chromatography (SEC) $[9,20]$. The new manganese(III) complex $[\mathrm{Mn}(\mathrm{papy})(\mathrm{acac})]$ has been synthesised and characterised; its activity is compared with a series of tripodal complexes. To gain insight into the reaction mechanisms by which complexes of the type [Mn(tripod)( $\beta$-diketonate)] react with peroxides, we studied the reactions of cumyl hydroperoxide and tert-butyl hydroperoxide with [Mn(pppy)(dpm)] using UV-vis and EPR spectroscopy.

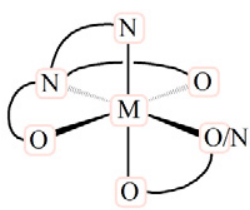

$\begin{array}{ll}\mathbf{H}_{2} \text { pppy }\left(\mathrm{R}^{1}, \mathrm{R}^{2}=\mathrm{H}\right) & \mathbf{H}_{2} \text { tbpppy }\left(\mathrm{R}^{1}, \mathrm{R}^{2}={ }^{\mathrm{t}} \mathrm{Bu}\right) \\ \text { Ia: }[\mathrm{Mn}(\mathrm{pppy})(\mathrm{acac})] & \text { IIa: }[\mathrm{Mn}(\mathrm{tbpppy})(\mathrm{acac})] \\ \text { Ib: }[\mathrm{Fe}(\mathrm{pppy})(\mathrm{acac})] & \text { IIb: }[\mathrm{Fe}(\mathrm{tbpppy})(\mathrm{acac})] \\ \text { Ic: }[\mathrm{Mn}(\mathrm{pppy})(\mathrm{dbm})] & \text { IIc: }[\mathrm{Mn}(\mathrm{tbpppy})(\mathrm{dpm})] \\ \text { Id: }[\mathrm{Mn}(\mathrm{pppy})(\mathrm{dpm})] & \text { IId: }[\mathrm{Mn}(\mathrm{tbpppy})(\mathrm{OAc})] \\ \text { Ie: }[\mathrm{Mn}(\mathrm{pppy})(\mathrm{quin})] & \\ & \\ \mathbf{H}_{\mathbf{2}} \text { dnpppy }\left(\mathrm{R}^{1}=\mathrm{NO}_{2}, \mathrm{R}^{2}=\mathrm{H}\right) & \mathbf{H}_{2} \text { papy } \\ \text { III: }[\mathrm{Mn}(\operatorname{dnpppy})(\mathrm{acac})] & \text { IV: }[\mathrm{Mn}(\text { papy })(\mathrm{acac})]\end{array}$

Scheme 2. Overview of the complexes.

\section{Experimental}

\subsection{Materials}

Technical ethyl linoleate (EL, 70\%; remainder ethyl oleate, ethyl palmitate and ethyl stearate [20]) was obtained from Fluka. The small amounts of hydroperoxides that are present in the EL were removed by passing the oil through a basic alumina column immediately before use. Cumyl hydroperoxide ( $80 \%$ in cumene) and $t$-butyl hydroperoxide (5.5 M solution in decane) purchased from Fisher Scientific were used as received. Other chemicals were all of reagent grade and used as received. The complex $\left[\mathrm{Mn}(\mathrm{III})(\mathrm{acac})_{3}\right]$ was prepared as described previously [21]. The synthesis and characterisation of the complexes with the tripodal ligands $\mathrm{H}_{2}$ pppy, $\mathrm{H}_{2}$ tbpppy, and $\mathrm{H}_{2}$ dnpppy have been reported elsewhere [18].

\subsection{Synthesis}

\subsection{1. $N$-(2-Hydroxybenzyl)glycine}

$N$-(2-Hydroxybenzyl)glycine was synthesised using an adaptation of a literature procedure [22]. Glycine $(6.0 \mathrm{~g}, 80 \mathrm{mmol})$ and potassium hydroxide $(4.5 \mathrm{~g}, 80 \mathrm{mmol})$ were dissolved in $40 \mathrm{~mL}$ of $\mathrm{H}_{2} \mathrm{O}$, and this mixture was added to one equivalent of salicylaldehyde $(9.6 \mathrm{~g}, 80 \mathrm{mmol})$ in EtOH. After $30 \mathrm{~min}$ of stirring, a solution of one equivalent of $\mathrm{NaBH}_{4}(3.0 \mathrm{~g}, 80 \mathrm{mmol})$ and a few drops of an aqueous sodium hydroxide solution was slowly added to the yellow mixture. After addition of the $\mathrm{NaBH}_{4}$, the reaction mixture was white and turbid. After stirring overnight, the solution was filtered and acidified to $\mathrm{pH} 4$ with concentrated hydrochloric acid. On cooling of the reaction mixture a white solid precipitated, which was collected by filtration and washed with a small amount of water. The product was obtained in $60 \%$ ( $4.31 \mathrm{~g})$ yield as a white powder. ${ }^{1} \mathrm{H}$ NMR ( $\mathrm{D}_{2} \mathrm{O}$ with some $\left.\mathrm{DCl}\right): 7.32$ (t, $\left.2 \mathrm{H}, \mathrm{ar}\right), 6.93$ (m, $2 \mathrm{H}$, ar), 4.27 (s, $2 \mathrm{H}, \mathrm{N}-\mathrm{CH}_{2}-\mathrm{Ar}$ ), 3.90 (s, $2 \mathrm{H}, \mathrm{N}-\mathrm{CH}_{2}-\mathrm{CO}_{2}$ ). IR (neat): 3108, 2548, 1564, 1489, 1460, 1435, 1410, 1378, $1335,1309,1278,1266,1254,1188,1185,1151,1112,1054$, $1030,972,917,874,850,826,763,686,616,590,544,512$, $474,459,332 \mathrm{~cm}^{-1}$. 


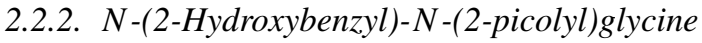 \\ ( $\mathrm{H}_{2}$ papy)}

This new ligand was synthesised through a slightly modified previously reported procedure [23]. To $11 \mathrm{mmol}$ (2 g) $\mathrm{N}$-(2hydroxybenzyl)glycine in dry $\mathrm{MeOH}$ was added one equivalent of potassium hydroxide (11 mmol, $0.62 \mathrm{~g})$, then one equivalent of pyridine-2-carboxaldehyde (11 mmol, $1.18 \mathrm{~g})$, yielding a clear yellow solution. After $2 \mathrm{~h}$ of stirring, one equivalent of $\mathrm{NaBH}_{4}$ (11 mmol, $0.41 \mathrm{~g}$ ) was slowly added, and the solution was stirred for $18 \mathrm{~h}$. After evaporation of the solvent, the residue was dissolved in water, and the solution was acidified with concentrated acetic acid to $\mathrm{pH} 3$. The reaction mixture was extracted three times with $30 \mathrm{~mL}$ of $\mathrm{CH}_{2} \mathrm{Cl}_{2}$. A white solid precipitated in the combined $\mathrm{CH}_{2} \mathrm{Cl}_{2}$ fractions. This solid was collected by filtration. This was the desired product in $32 \%(0.95 \mathrm{~g})$ yield. ${ }^{1} \mathrm{H} \mathrm{NMR}\left(\mathrm{D}_{2} \mathrm{O}\right): 8.60(\mathrm{~d}, 1 \mathrm{H}$, py), 7.90 (t, 1H, py), 7.40 (dt, 5H, py,ar), 6.86 (m, 2H, ar), 4.53 (s, 2H, N-CH ${ }_{2}$-py), 4.48 (s, 2H, N-CH - -ar), 3.84 (s, 2H, $\mathrm{N}-\mathrm{CH}_{2}-\mathrm{CO}_{2}$ ). IR (neat): $3397,3007,1858,1704,1628,1594$, 1460, 1436, 1392, 1347, 1307, 1274, 1254, 1200, 1185, 1150, 1114, 1031, 992, 914, 896, 836, 783, 757, 728, 702, 614, 548, $524,507,458,415 \mathrm{~cm}^{-1}$.

\subsubsection{Synthesis of $[\mathrm{Mn}(\mathrm{III})($ papy $)($ acac $)]($ IV $)$}

A solution of $0.735 \mathrm{mmol}(200 \mathrm{mg}) \mathrm{H}_{2}$ papy with 2 equiv of triethylamine $(209 \mu \mathrm{L})$ in $5 \mathrm{~mL}$ of $\mathrm{CH}_{2} \mathrm{Cl}_{2}$ was added to a solution of $0.735 \mathrm{mmol}(0.25 \mathrm{~g})$ of [ $\left.\mathrm{Mn}(\mathrm{acac})_{3}\right]$ in $5 \mathrm{~mL}$ of $\mathrm{CH}_{2} \mathrm{Cl}_{2}$. The resulting green reaction mixture was stirred overnight. The solvent was evaporated, and the residue was taken up in acetone. Petroleum ether (40-60) was slowly added until a precipitate was visible. After another 15 min of stirring, the precipitate was filtered off and dried in vacuo over $\mathrm{P}_{2} \mathrm{O}_{5}$. The product was a dark-green powder, yield 63\% (196 mg). Single crystals were obtained by keeping the acetone/petroleum ether filtrate at $-20^{\circ} \mathrm{C}$. Elem. analysis found (calc) for $\mathrm{C}_{20} \mathrm{H}_{21} \mathrm{MnN}_{2} \mathrm{O}_{5}$ : C: 56.52 (56.61), H: 5.40 (4.99), N: 6.42 (6.60)\%. IR (neat): 3500, 1646, 1604, 1564, 1517, 1478, 1456, 1442, 1353, 1261, 1100, 1018, 920, 892, 796, 760, 732, 679, 636, 528, 460, 416, $390 \mathrm{~cm}^{-1}$.

\subsection{Physical measurements}

${ }^{1} \mathrm{H}$ NMR measurements were carried out on a $200 \mathrm{MHz}$ Jeol FX-200 spectrometer equipped with a Tecmag data station. Infrared spectroscopy was done on a Perkin-Elmer 1000 FT-IR spectrophotometer with a diamond ATR device. UV-vis spectra were recorded on a Varian Cary 50 spectrophotometer, and elemental analysis on $\mathrm{C}, \mathrm{H}$, and $\mathrm{N}$ was performed with a Perkin-Elmer series II CHNS/O Analyzer 2400. CV measurements were done in $\mathrm{CH}_{2} \mathrm{Cl}_{2}$ solution with an Autolab PGSTAT 10 potentiostat using an $\mathrm{Ag} / \mathrm{AgCl}$ reference electrode, a Pt working electrode, and a Pt counter electrode with $0.1 \mathrm{M}$ tetrabutylammonium hexafluoridophosphate as an electrolyte.

\subsection{Reactivity studies}

\subsubsection{FTIR and SEC measurements}

The FTIR and SEC measurements were performed as described previously $[9,10]$. Due to small differences in the configuration of the HPLC system (e.g., the number of detectors used), the $x$-coordinate (elution volume in $\mathrm{mL}$ ) of a peak in a size-exclusion chromatogram can vary slightly between different sets of measurements.

\subsubsection{EPR measurements}

Electron paramagnetic resonance measurements were performed using a JEOL JES-RE2X ESR spectrometer with a JEOL X-band microwave, a JEOL electromagnet, and a JEOL ESPRIT 330 ESR Datasystem unit. A special quartz Dewar flask was used for measurements at liquid nitrogen temperature (77 K).

\subsubsection{Reaction of [Mn(pppy)(dpm)] with cumyl hydroperox-} ide at room temperature Before the actual experiment a spectrum was recorded of the empty EPR tube with solid DPPH as an external reference, thereafter keeping the parameters exactly the same for the experiment (freq. $=9.434 \mathrm{GHz}$, power $=$ $4 \mathrm{~mW}$, receiver gain $=1000$, field modulation $100 \mathrm{kHz}$, field modulation width $=1 \mathrm{mT}$, sweep width 220-420 mT, sweep time $1 \mathrm{~min}) .2 .12 \mathrm{mg}(3.8 \mu \mathrm{mol})[\mathrm{Mn}(\mathrm{pppy})(\mathrm{dpm})]$ was dissolved in $300 \mu \mathrm{L}$ of toluene. $4 \mu \mathrm{L}(\sim 24 \mu \mathrm{mol}$, six equivalents based on the complex) of cumyl hydroperoxide was transferred into the EPR tube, followed by the toluene solution; then the EPR spectra were recorded at 1.5 min intervals.

\subsubsection{Reaction of [Mn(pppy)(dpm)] with t-butyl hydroper-} oxide EPR measured in frozen solution $(77 \mathrm{~K}): 5 \mu \mathrm{L} t$-butyl hydroperoxide solution $(27.5 \mu \mathrm{mol})$ was brought into an EPR tube. Then, $800 \mu \mathrm{L}$ of a $1.3 \mathrm{mmol}$ solution of $[\mathrm{Mn}(\mathrm{pppy})(\mathrm{dpm})]$ in toluene $(1 \mu \mathrm{mol})$ was added, and the EPR tube was quickly stoppered and frozen in liquid nitrogen. The EPR spectrum was measured using the following parameters: freq. $=9.115 \mathrm{GHz}$, power $=5 \mathrm{~mW}$, receiver gain $=1000$, field modulation $100 \mathrm{kHz}$, field modulation width $=0.4 \mathrm{mT}$, sweep width $220-420$ or $310-330 \mathrm{mT}$, sweep time $4 \mathrm{~min}$. The measurement was carried out in the absence of DPPH to observe all radical signals unperturbed. After the desired spectrum was recorded, the spectrum was again recorded in the presence of DPPH as an external reference to establish a reference field value.

\subsubsection{UV-vis measurements}

Solution UV-vis spectra were recorded with a Varian Cary 50 spectrophotometer. First, $3 \mathrm{~mL}$ of a $0.25 \mathrm{mmol}$ solution of [Mn(pppy)(dpm)] in $\mathrm{CH}_{3} \mathrm{CN}$ was brought into a quartz cuvette; then $1 \mu \mathrm{L}$ of cumyl hydroperoxide $80 \%$ was dissolved in $100 \mu \mathrm{L}$ $\mathrm{CH}_{3} \mathrm{CN}$. From this solution, a $18 \mu \mathrm{L}$ ( $\sim 2$ eq based on complex) sample was obtained and added to the cuvette. Then the UVvis spectra of the reaction mixture were recorded automatically each hour for up to $17 \mathrm{~h}$. 
Table 1

Selected bond lengths $(\AA)$ and angles $\left(^{\circ}\right)$ for complex IV

\begin{tabular}{lclc}
\hline Mn1-N102 & $2.261(2)$ & Mn1-O102 & $2.0968(19)$ \\
Mn1-N101 & $2.129(2)$ & Mn1-O201 & $1.931(2)$ \\
Mn1-O101 & $1.863(2)$ & Mn1-O202 & $1.941(2)$ \\
N102-Mn1-N101 & $75.38(9)$ & O102-Mn1-N102 & $154.50(8)$ \\
O101-Mn1-O102 & $93.93(9)$ & O102-Mn1-N101 & $79.62(8)$ \\
O101-Mn1-O201 & $175.50(9)$ & O201-Mn1-O202 & $89.69(8)$ \\
O101-Mn1-O202 & $88.50(9)$ & O201-Mn1-N102 & $84.26(10)$ \\
O101-Mn1-N102 & $92.25(10)$ & O201-Mn1-N101 & $89.03(10)$ \\
O101-Mn1-N101 & $92.84(10)$ & O202-Mn1-N102 & $105.33(9)$ \\
O102-Mn1-O201 & $90.44(9)$ & O202-Mn1-N101 & $178.47(10)$ \\
O102-Mn1-O202 & $99.54(8)$ & &
\end{tabular}

\subsection{X-ray data collection and structure determination}

A black single crystal of the complex [Mn(III)(papy)(acac)] was selected and transferred into the cold nitrogen stream $(150 \mathrm{~K})$ on a Nonius KappaCCD diffractometer with graphitemonochromated $\operatorname{Mo} K_{\alpha}$ radiation $(\lambda=0.71073 \AA)$ from a rotating anode source. The data were processed with EVALCCD and SADABS. The structure was solved by Direct Methods with SHELXS-86 [24] and refined by least squares with SHELXL97 [25] against $F^{2}$ with all reflections. A small amount of disordered solvent (in four solvent accessible voids of $112 \AA^{3}$ each) was taken into account by back-Fourier transformation in the structure factor calculations following the PLATON/SQUEEZE procedure. Hydrogen atoms were introduced at calculated positions and refined riding on their carrier atoms. One of the two crystallographically independent molecules was found to be slightly disordered (atom C501) and refined with a 57:43\% disorder model. Molecular illustration, checking for higher symmetry and geometry calculations were performed with the PLATON package [26]. Crystallographic data: $\mathrm{C}_{20} \mathrm{H}_{21} \mathrm{MnN}_{2} \mathrm{O}_{5}$ *, $M_{\mathrm{r}}=424.33^{*}$, orthorhombic, space group $P$ na2 ${ }_{1}$ (no. 33), $Z=8, a=21.0513(15), b=11.2954(10), c=17.8209(19) \AA$, $V=4237.5(7) \AA^{3}, T=150 \mathrm{~K}, F(000)=1128^{*}, \mu\left(\operatorname{Mo} K_{\alpha}\right)=$ $0.687 \mathrm{~mm}^{-1 *}, 63109$ reflections measured $\left(R_{\sigma}=0.0440\right)$, 8119 unique ( $R_{\text {int }}=0.0789$ ), $R=0.0377, w R 2=0.0897, S=$

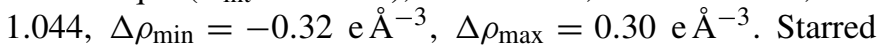
quantities are without the contribution of the disordered solvent.

\section{Results}

\subsection{Synthesis and characterisation of potential drier complexes}

The synthesis, spectroscopic characterisation, and structures of the complexes I-III have been described elsewhere [18]. For the complex [Mn(papy)(acac)] (IV), single crystals were obtained, and the crystal structure was determined. Table 1 presents a selection of molecular bond lengths and angles.

The crystal structure of complex IV contains two crystallographically independent but chemically equivalent molecules in the asymmetric unit. One of the acac- $\mathrm{CH}_{3}$ groups in one of these complexes is disordered over two positions. Only the data for the nondisordered molecule are listed in Table 1; bond

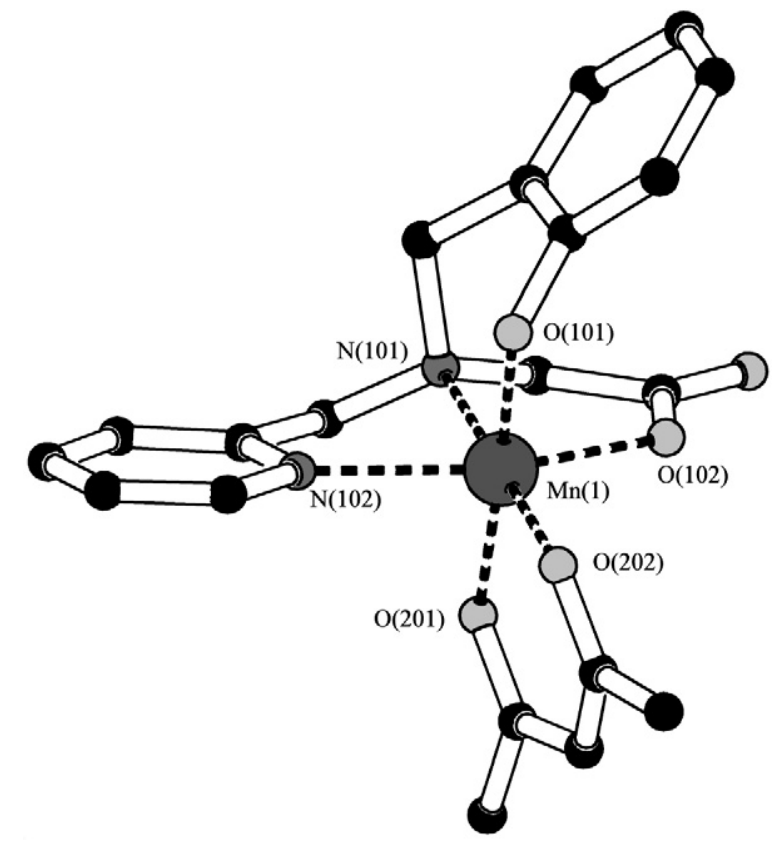

Fig. 1. Projection of the structure of [Mn(papy)(acac)] IV. Hydrogen atoms are omitted for clarity.

lengths and angles for $\mathrm{Mn}(2)$ are almost the same as for $\mathrm{Mn}(1)$. A PLATON/PLUTON representation of the molecular structure of complex IV is shown in Fig. 1. The Mn(III) ion in IV has a distorted octahedral coordination geometry, just as the other $[\mathrm{Mn}(\mathrm{III})($ tripod $)(\beta$-diketonate) $]$ complexes reported earlier [18]. In contrast with the pppy-complexes Ia, Ic, and Id, however, complex IV has both oxygen donor atoms of the acac ligand (O202 and O201) in the equatorial plane, together with the amine nitrogen atom N101 and the phenolate oxygen atom O101. The Jahn-Teller axis of the $\mathrm{d}^{4} \mathrm{Mn}(\mathrm{III})$ ion is located along the bonds Mn1-N(pyridine) and Mn1-O(carboxylate). The N(pyridine)-Mn1 bond length is slightly longer than observed for the other $[\mathrm{Mn}(\mathrm{III})($ tripod $)(\beta$-diketonate $)]$ complexes [18]. The bond lengths of the phenolate oxygen and the amine nitrogen to the manganese center are both comparable to those in the Ia, Ic, and Id complexes. The acac ligand is coordinated symmetrically, with similar bond lengths for both oxygens. The acac ligand is not folded over the O201-O202 axis, but the acac-Mn chelate ring is slightly puckered, as indicated by a small torsion angle of $5.5(3)^{\circ}$ between the two $\mathrm{C}-\mathrm{O}$ groups in the acac ligand.

Cyclic voltammetry was used to compare the oxidising power of the potential paint drier complexes [18]. The cyclic voltammogram of [Mn(papy)(acac)] IV is shown in Fig. 2. The redox couple $1\left(1_{\mathrm{ox}}=0.96 \mathrm{~V} ; 1_{\text {red }}=0.78 \mathrm{~V}\right)$ of complex IV with an $E_{1 / 2}$ value of $0.87 \mathrm{~V}$ versus $\mathrm{Ag} / \mathrm{AgCl}$ for the oxidation of $\mathrm{Mn}(\mathrm{III})$ to $\mathrm{Mn}(\mathrm{IV})$ was quite similar to that of [Mn(dnpppy)(acac)] III [18]. The electron-withdrawing $\mathrm{NO}_{2}$ groups on both phenolate arms of the tripodal ligand apparently had the same effect on the total electron density at the metal atom as the substitution of one phenolate arm of the tripodal ligand for a carboxylate group. The lower donor capacity of the ligands papy and dnpppy resulted in a 


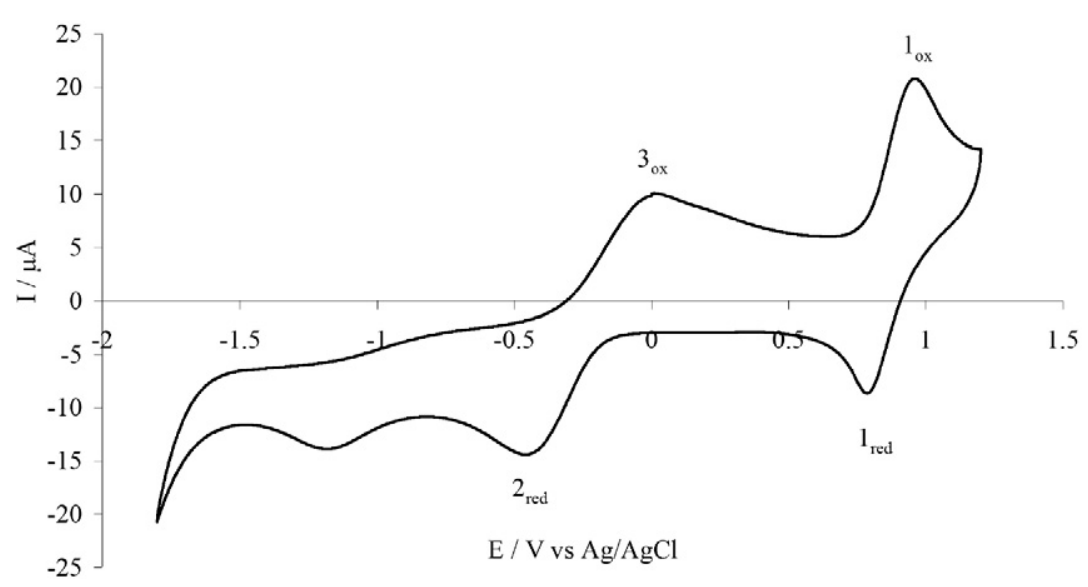

Fig. 2. Cyclic voltammogram of the complex [Mn(papy)(acac)] IV. Scan rate: $200 \mathrm{mV} / \mathrm{s}$.

metal centre that is much easier to reduce; the peak potential $2_{\text {red }}$ of complex IV $(-0.39 \mathrm{~V})$ was shifted to a considerably more positive potential relative to the value for complex Ia $(-1.08 \mathrm{~V})[18]$. However, the reduction of $\left[\mathrm{Mn}^{\mathrm{III}}\right.$ (papy)(acac)] to $\left[\mathrm{Mn}^{\mathrm{II}}(\text { papy)(acac) }]^{-}\right.$was irreversible; another species with an oxidation at $3_{\text {ox }}(-0.01 \mathrm{~V})$ was formed in solution. Accordingly, the redox couple 1 for the oxidation to Mn(IV) also shifted to a significantly more positive $E_{1 / 2}$ value $(0.61 \mathrm{~V}$ for Ia) and became more reversible, indicating greater stability for $\left[\mathrm{Mn}^{\mathrm{IV}}(\text { papy })(\mathrm{acac})\right]^{+}$than for $\left[\mathrm{Mn}^{\mathrm{IV}} \text { (pppy)(acac) }\right]^{+}$.

\subsection{Autoxidation activity determined with FTIR and SEC}

To test the new complexes I-IV for their potential paintdrying capacities, the rate of EL autoxidation was determined for each complex, using the FTIR method reported earlier [9]. The Mn(III) complexes themselves are not air-sensitive and are quite stable over long periods (days) in solution; no changes to the spectrum of the complexes were observed by UV-vis measurements in solution in air. Reaction occurred only with both EL and dioxygen present or with hydroperoxides present, as demonstrated by the EPR and UV-vis experiments (Section 3.3). When hydroperoxides were removed from EL, autoxidation was initiated only when dioxygen was present as well.

All autoxidation reactions were performed using purified EL, that is, EL from which all hydroperoxides have been removed [7]. The EL autoxidation rates for each complex are collected in Table 2. For nearly all complexes, the autoxidation reaction proceeded at two different rates over the course of the measurement: after the induction time, the reaction started with a high initial rate (termed rate 1), which changed to a lower rate (termed rate 2) after a certain time interval. This time interval, the "duration of rate 1," is also given in Table 2 for those complexes that show two different rates. The FTIR plot for the autoxidation of EL catalysed by [Mn(pppy)(dpm)] (Id) is shown in Fig. 3 as a typical example. For the manganese complexes with a tbpppy ligand (II), no clear discrimination could be made between different rates, and, consequently, only the initial rate is listed in Table 2.

The FTIR plots obtained for the complexes IIa,c,d, III, and IV are shown in Fig. 4. The two iron complexes, [Fe(pppy)-

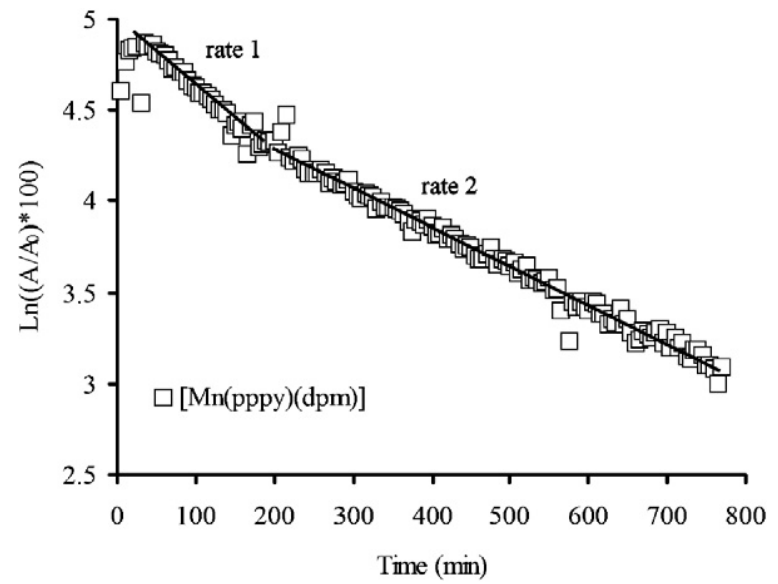

Fig. 3. Logarithmic plot of the percentage of decrease of the IR $3010 \mathrm{~cm}^{-1}$ peak area integrals of EL vs time for [Mn(pppy)(dpm)] (Id).

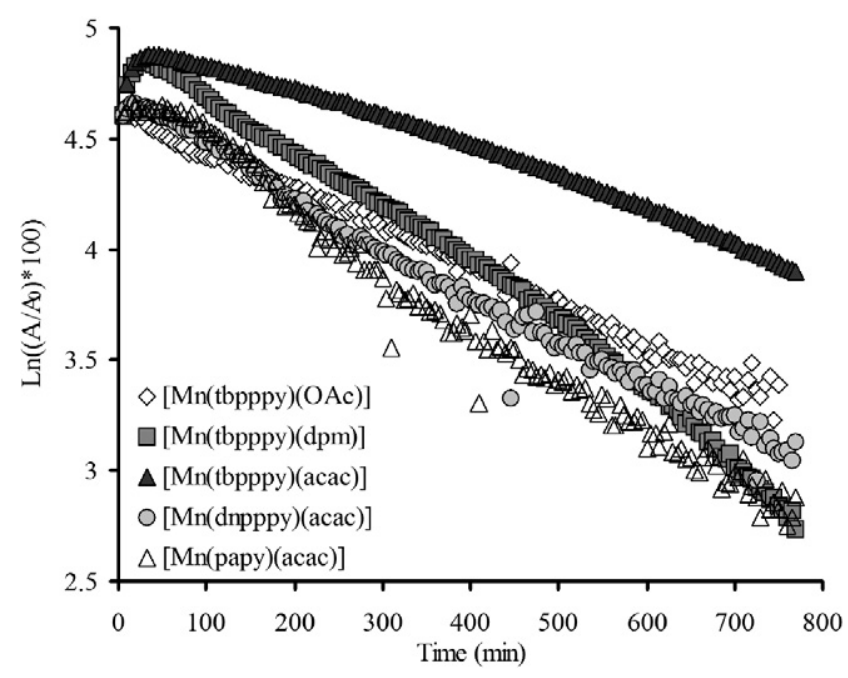

Fig. 4. Logarithmic plots of the percentage of decrease of the IR $3010 \mathrm{~cm}^{-1}$ peak area integrals of EL vs time for the complexes IIa,c,d, III, and IV.

(acac)] (Ib) and [Fe(tbpppy)(acac)] (IIb), did not show any catalytic activity in the autoxidation of EL.

The activity for crosslink-formation and oligomerisation of EL was examined for the selected complexes Ia,d, IIa,d, III, 
Table 2

The induction times and autoxidation rates for the autoxidation of purified EL, catalysed by the complexes I-IV as determined with FTIR

\begin{tabular}{|c|c|c|c|c|}
\hline Compound & & $\begin{array}{l}\text { Induction } \\
\text { time (min) }\end{array}$ & $\begin{array}{l}\text { Rate } 1^{\mathrm{a}}\left(\times 10^{-3} \mathrm{~min}^{-1}\right) / \\
\text { duration }(\mathrm{min})\end{array}$ & $\begin{array}{l}\text { Rate } 2^{\mathrm{a}} \\
\left(\times 10^{-3} \mathrm{~min}^{-1}\right)\end{array}$ \\
\hline Ia & {$[\mathrm{Mn}(\mathrm{III})(\mathrm{pppy})(\mathrm{acac})]$} & $<25$ & $4 / 155$ & 2 \\
\hline Ib & {$[\mathrm{Fe}(\mathrm{III})(\mathrm{pppy})(\mathrm{acac})]$} & - & Not active & \\
\hline Ic & {$[\mathrm{Mn}(\mathrm{III})(\mathrm{pppy})(\mathrm{dbm})]$} & $<10$ & $6 / 85$ & 3 \\
\hline Id & {$[\mathrm{Mn}(\mathrm{III})(\mathrm{pppy})(\mathrm{dpm})]$} & 40 & $4 / 120$ & 2 \\
\hline Ie & {$[\mathrm{Mn}(\mathrm{III})(\mathrm{pppy})(\mathrm{quin})]$} & 75 & $3 / 225$ & 2 \\
\hline IIa & {$[\mathrm{Mn}(\mathrm{III})(\mathrm{tbpppy})(\mathrm{acac})]$} & 45 & 1 & \\
\hline IIb & {$[\mathrm{Fe}(\mathrm{III})(\mathrm{tbpppy})(\mathrm{acac})]$} & - & Not active & \\
\hline IIc & {$[\mathrm{Mn}(\mathrm{III})(\mathrm{tbpppy})(\mathrm{dpm})]$} & 40 & 3 & \\
\hline IId & {$[\mathrm{Mn}(\mathrm{III})(\mathrm{tbpppy})(\mathrm{OAc})]$} & 30 & 2 & \\
\hline III & {$[\mathrm{Mn}(\mathrm{III})(\mathrm{dnpppy})(\mathrm{acac})]$} & 40 & $3 / 270$ & 2 \\
\hline \multirow[t]{2}{*}{ IV } & {$[\mathrm{Mn}(\mathrm{III})($ papy $)(\mathrm{acac})]$} & 80 & $4 / 220$ & 2 \\
\hline & $\mathrm{Co}-\mathrm{EH}^{\mathrm{b}}$ & 0 & 3 & \\
\hline
\end{tabular}

a The average error in the rates is about $20 \%$.

b Co-EH is cobalt(II) 2-ethylhexanoate, the commercial paint drier, given here as a reference.

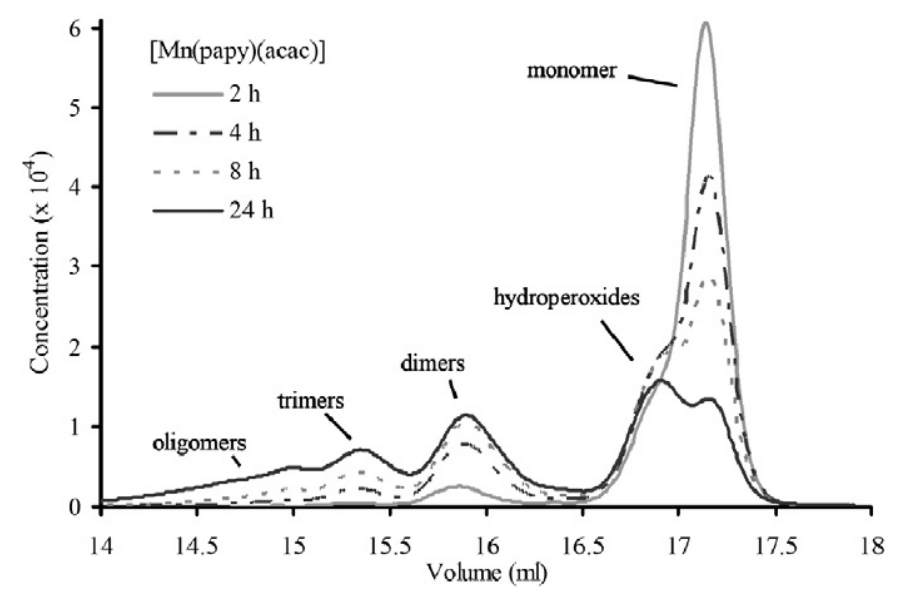

Fig. 5. Size exclusion chromatograms for the autoxidation of unpurified EL, catalysed by the complex $[\mathrm{Mn}($ papy)(acac)] IV, measured after different EL autoxidation times.

and IV using SEC as described previously [10]. All SEC experiments were performed using unpurified EL, to minimize the induction times. The initiation characteristics are better evaluated through the FTIR measurements, and are not important for the oligomerisation experiments. A representative chromatogram for the catalyst [Mn(papy)(acac)] IV is shown in Fig. 5; the chromatograms of the other complexes are very similar, with only some differences in the relative amount of peroxides (supplementary material, Fig. S1). Both compounds with a pppy ligand, complexes Ia and Id, showed a steady increase in the ROOH concentration over a period of $8 \mathrm{~h}$. The complexes IIa and IV also demonstrated an increased $\mathrm{ROOH}$ concentration in $8 \mathrm{~h}$, but the total concentration reached in $8 \mathrm{~h}$ was lower than that for the complexes with a pppy ligand. For the complexes IId and III, a maximum ROOH concentration was attained between 6 and $8 \mathrm{~h}$ of reaction time; the ROOH concentration after $8 \mathrm{~h}$ was lower than after $6 \mathrm{~h}$. Although different complexes showed slightly different trends in the time evolution of the ROOH peak, the chromatogram after $24 \mathrm{~h}$ was very similar for each complex.

\subsection{The reaction of $[M n(p p p y)(d p m)]$ Id with hydroperoxides studied with UV-vis and EPR spectroscopy}

To gain more insight in the reaction mechanisms by which the manganese complexes might function as autoxidation catalysts, complex Id was reacted with alkyl hydroperoxides. Complex Id was selected as a general example for all complexes of the type $[\mathrm{Mn}(\mathrm{III})$ (tripod) $(\beta$-diketonate)]. The EPR and UVvis experiments with cumyl hydroperoxide and tert-butyl hydroperoxide were performed under argon, to exclude reactions with dioxygen and enhance resolution and signal-to-noise ratio.

Cumyl hydroperoxide (2-phenyl-prop-2-yl hydroperoxide) or $t$-butyl hydroperoxide were added to the complex in solution, and the changes in the UV-vis or the EPR spectra over time were monitored. The changes in the UV-vis spectrum of complex Id in $\mathrm{CH}_{3} \mathrm{CN}$ solution after addition of two equivalents of cumyl hydroperoxide was monitored for $500 \mathrm{~min}$, and a spectrum was recorded each hour (supplementary material, Fig. S2). The two most obvious changes in the spectrum were an increased intensity of the peak at $430 \mathrm{~nm}$ and a decreased absorption at $321 \mathrm{~nm}$, giving rise to an isosbestic point at $334 \mathrm{~nm}$. When the reaction time was extended beyond $500 \mathrm{~min}$ (up to $1000 \mathrm{~min}$ ), all absorptions in the spectrum decreased slowly at a constant rate.

The reaction was also monitored using X-band EPR spectroscopy at room temperature. Representative EPR spectra are shown in Fig. 6. To a dark red/brown solution of [Mn(pppy)$(\mathrm{dpm})]$ in toluene was added six equivalents of cumyl hydroperoxide, and the EPR spectra of the resulting solution were recorded at 1.5-min intervals, for up to $15 \mathrm{~min}$. After $15 \mathrm{~min}$, a brown precipitate was visible in the EPR tube, and the colour of the remaining solution turned from dark red/brown to brown. Immediately after addition of the alkyl hydroperoxide, a large radical signal was visible at $335 \mathrm{mT}(g=2.0104)$. Over time, this radical signal decreased, and a broad, six-line signal typical of $\mathrm{Mn}$ (II) appeared at $334 \mathrm{mT}(g=2.0181)$, which is normal for $\mathrm{Mn}(\mathrm{II})$. The manganese(II) signal was split into six lines by the ${ }^{55} \mathrm{Mn}$ nucleus, which had a nuclear spin of $5 / 2$. The aver- 

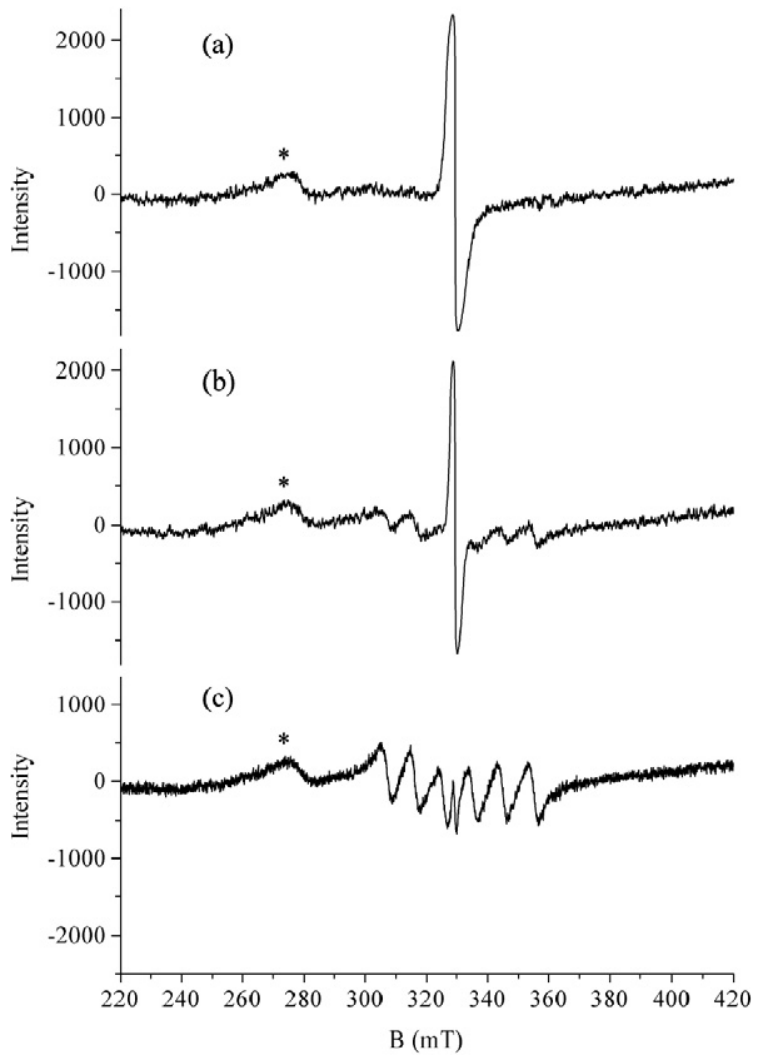

Fig. 6. Room-temperature X-band EPR spectra of a toluene solution of [Mn(pppy)(dpm)] Id $(13 \mathrm{mM})$ with 6 eq of cumyl hydroperoxide added, recorded after (a) 1, (b) 4, and (c) $10 \mathrm{~min}$. Conditions are given in Section 2. The signal indicated with * is due to an impurity in the cavity.

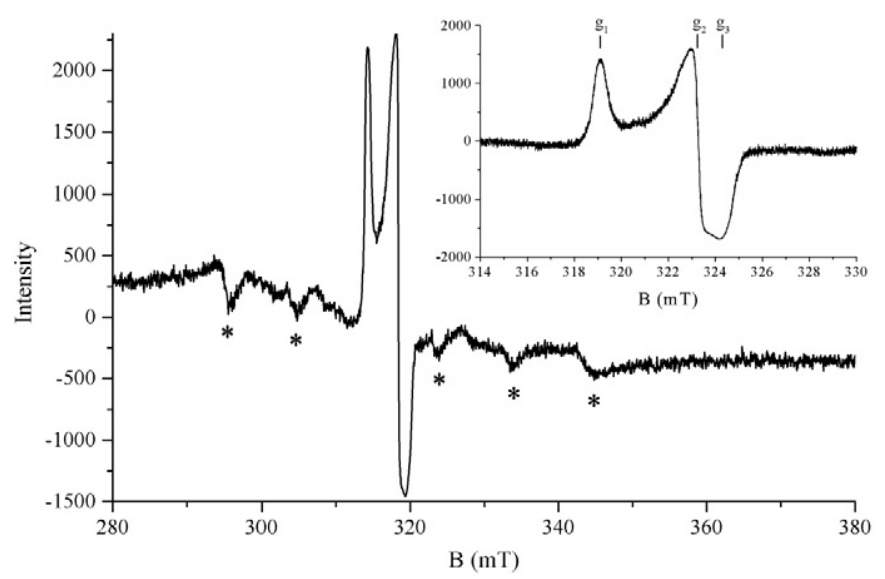

Fig. 7. Frozen solution (77 K) X-band EPR spectrum of [Mn(pppy)(dpm)] Id $(1.3 \mathrm{mM})$ in toluene with $27.5 \mathrm{eq}$ of tert-butyl hydroperoxide added. The inset shows a magnification of the $314-330 \mathrm{mT}$ range. Signals with $*$ are due to Mn(II). Conditions are given in Section 2. age coupling constant due to the manganese hyperfine coupling was $95 \mathrm{G}$.

To gain further insight into the reaction of Id with hydroperoxides, the reaction mixture of Id in toluene was immediately frozen in liquid nitrogen directly after the addition of $27.5 \mathrm{eq}$ of $t$-butyl hydroperoxide. The frozen solution EPR spectrum of this reaction mixture is depicted in Fig. 7. A large, anisotropic, radical signal is visible, with components at $320 \mathrm{mT}\left(g_{1}=\right.$ $2.0353), 324 \mathrm{mT}\left(g_{2}=2.0095\right)$, and $325 \mathrm{mT}\left(g_{3}=2.0039\right)$ (Fig. 7, inset). The broad Mn(II) signal, which at room temperature was not visible until after several minutes, was immediately noticeable in the frozen solution spectrum. The EPR spectrum measured directly after thawing the frozen solution showed a single radical signal, just as was observed for the experiment with cumyl hydroperoxide (Fig. 5a, spectrum after $1 \mathrm{~min}$ ). Subsequent EPR spectra at room temperature showed the same trend as for the reaction with cumyl hydroperoxide, a decreased radical signal over time and an increased six-line signal characteristic for manganese(II).

\section{Discussion}

\subsection{The reaction of $[M n(p p p y)(d p m)]$ with hydroperoxides}

The high radical signal observed in the room temperature EPR spectra (Fig. 6) of the reaction of complex Id with cumyl hydroperoxide quickly decreased to form a growing signal arising from Mn(II). The UV-vis spectra showed a decrease in the peak at $321 \mathrm{~nm}$. This peak was assigned as the MLCT transition from the manganese ion to the dpm ligand [18]. On reaction with cumyl hydroperoxide, the coordination mode of the dpm ligand apparently changed, or dpm dissociated from the complex; thus, the specific Mn $\rightarrow$ dpm MLCT transition disappeared. The EPR measurement at $77 \mathrm{~K}$ supports the idea that the secondary ligand was replaced; the anisotropic radical signal in Fig. 7 has been linked to a coordinated peroxyl radical $[27,28]$. Thus, the species responsible for the radical signal is proposed to be $\left[\mathrm{Mn}(\mathrm{III})(\mathrm{pppy})(\mathrm{OH})\left({ }^{t} \mathrm{BuOO}^{*}\right)\right]$. Scheme 3 proposes a set of reactions for the reaction of complex Id with an alkyl hydroperoxide, based on the observations in the UV-vis and EPR and in analogy with a similar mechanism reported for the reaction of $\left[\mathrm{Co}(\mathrm{acac})_{2}\right]$ with ${ }^{t} \mathrm{BuOOH}$ [29]. Although the experiments with alkyl hydroperoxides were performed with complex Id, the mechanism is expected to be valid for all of the $\mathrm{Mn}(\mathrm{III})$ tripodal ligand complexes. At room temperature, the formed species $\left[\mathrm{Mn}(\mathrm{III})(\mathrm{pppy})(\mathrm{OH})\left({ }^{t} \mathrm{BuOO}^{*}\right)\right]$ likely react rapidly with other $t$-butylhydroperoxide molecules, resulting in a decrease of the radical signal and formation of $\mathrm{Mn}(\mathrm{II})$.

$$
\begin{array}{ll}
{[\mathrm{Mn}(\mathrm{III})(\mathrm{pppy})(\mathrm{dpm})]+{ }^{t} \mathrm{BuOOH} \rightarrow[\mathrm{Mn}(\mathrm{II})(\mathrm{pppy})(\mathrm{Hdpm})]+{ }^{t} \mathrm{BuOO} \cdot} & \mathbf{1} \\
{[\mathrm{Mn}(\mathrm{II})(\mathrm{pppy})(\mathrm{Hdpm})]+{ }^{t} \mathrm{BuOOH} \rightarrow[\mathrm{Mn}(\mathrm{III})(\mathrm{pppy})(\mathrm{OH})]+\mathrm{Hdpm}+{ }^{t} \mathrm{BuO} \cdot} & \mathbf{2} \\
{[\mathrm{Mn}(\mathrm{III})(\mathrm{pppy})(\mathrm{OH})]+{ }^{t} \mathrm{BuOO}^{*} \rightarrow\left[\mathrm{Mn}(\mathrm{III})(\mathrm{pppy})(\mathrm{OH})\left({ }^{t} \mathrm{BuOO}^{\cdot}\right)\right]} & \mathbf{3}
\end{array}
$$

Scheme 3. Proposed reaction mechanism for the reaction of $[\mathrm{Mn}(\mathrm{III})(\mathrm{pppy})(\mathrm{dpm})] \mathbf{I d}$ with $t$-butyl hydroperoxide, forming a coordinated $t$-butyl peroxyl radical species. 

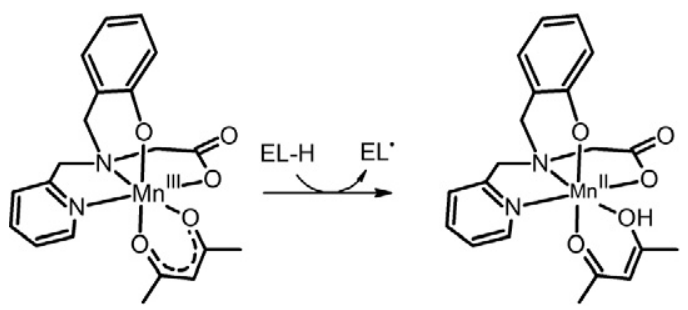

Scheme 4. Proposed reaction mechanism for the initiation of EL-autoxidation by tripodal ligand complexes, in this example the reaction is shown for complex IV.

\subsection{Autoxidation and oligomerisation activities}

Except for compounds IIa,c and IId, which contain the tbpppy ligand, all manganese tripodal ligand complexes showed the same trend in the autoxidation of (purified) EL. After a short induction time, the reaction began at a relatively high rate for a varying period (95-270 min). The high initial rate then changed to a lower rate, which again was constant and on average was the same for all complexes. Because the final rate was constant, the change in rate most likely was not related simply to a decreased concentration of the active catalyst, but rather to a change in the structure of the catalytically active complex. Another feature that the complexes have in common is the short induction time. A short induction time indicates that the complexes are able to initiate the autoxidation reaction, because initially no peroxides are present in the purified EL. Initiation requires reduction of $\mathrm{Mn}$ (III) to $\mathrm{Mn}$ (II) [8]. As discussed in the previous section, the complexes are readily reduced by alkyl hydroperoxides (reaction 1 in Scheme 3). Because the bond dissociation energy of the ROO-H bond $\left(90 \mathrm{kcal} \mathrm{mol}^{-1}\right)$ is higher than that of a double-allylic R-H bond $\left(80 \mathrm{kcal} \mathrm{mol}^{-1}\right)$ [30], the tripodal ligand complexes also should be capable of reacting directly with EL, thus initiating the reaction.

Scheme 4 illustrates this reaction pathway. The uncharged secondary ligand that is formed will not coordinate very strongly to the metal center and can dissociate from the complex. The structural fragment that remains, [Mn(II)(tripod)], is nearly the same for all of the synthesised compounds. Consequently, a catalytically active complex that is structurally very similar for each of the complexes may be formed over the course of the reaction, regardless of the structure of the starting complex. This assumption is supported by the observation of similar values for "rate 2" (see Table 2) for almost all complexes. It seems that the catalyst that is formed is quite stable, because the reaction proceeds at the constant "rate 2" for a significant time interval. More studies are needed to elucidate the exact structure of the species responsible for rate 2 .

The high initial rate 1 might simply be a consequence of the initiation of radical chain reactions by the direct reaction of the starting complex with EL. Once the entire complex has been transformed (as shown in Scheme 4) and the secondary ligand has dissociated, direct initiation may no longer be possible, and the autoxidation reaction proceeds predominantly through hydroperoxide decomposition.

The FTIR plots of the complexes with a tbpppy ligand do not show the pronounced change in autoxidation rate observed for the other tripodal ligand complexes. This observation can be explained by the assumption that the fragment [Mn(II)(tbpppy)] is more stable than the fragment [Mn(II)(tripod)] for complexes with other tripodal ligands, due to the electron-donating $t$-butyl groups. Consequently, the secondary ligand can more easily dissociate from the complex, and the catalytic structure responsible for rate 2 in the other complexes can form much more quickly.

The autoxidation rate for the compound [Mn(III)(tbpppy)(acac)] (IIa) is quite low compared with the rates for other tripodal ligand complexes, only $1 \times 10^{-3} \mathrm{~min}^{-1}$ (see Table 2 and Fig. 4). Complex IIa is also the only complex to show reversible ligand oxidation [18], which might explain the observed lower reactivity. The complex will be less reactive if coordinated radicals are stabilised by delocalisation of the radical over the phenolate arms.

The two iron complexes are not active in the autoxidation of EL, probably because it is too difficult to reduce Fe(III) to $\mathrm{Fe}(\mathrm{II})$. Often in oxidation catalysis with iron complexes, polypyridyl ligands are used [31-34]. These polypyridyl ligands are generally good $\sigma$-donors, and moderate-to-weak $\pi$ donors [35]. The dianionic tripodal ligands used in this study are good $\sigma$-donors and good $\pi$-donors as is clear from the UV-vis studies [18]. Apparently, the dianionic tripodal ligands donate too much electron density to the metal, thereby stabilising the $\mathrm{Fe}(\mathrm{III})$ ion and preventing reduction to $\mathrm{Fe}(\mathrm{II})$.

The time-resolved SEC studies of EL catalysed by the selected complexes Ia,d, IIa,d, III, and IV show little difference for each complex, with some differences observed only in the time evolution of the hydroperoxide peak. For all complexes, the chromatograms show the formation of dimers, trimers, and oligomers in the same time period and in roughly the same concentrations relative to the monomer peak. The chromatograms measured after $24 \mathrm{~h}$ of reaction are all very similar. This observation compares well with the postulation that the catalytically active complexes formed over the course of the autoxidation are analogous for each complex.

\subsection{Tripodal ligand complexes as potential paint driers}

Although the only way to really determine whether a complex is a good paint drier is to test it as a drier in alkyd paint, some predictions can be made based on the results discussed in this paper. Basically, all manganese complexes except complex IIa showed autoxidation activity in the autoxidation of EL greater than that of the complex $\left[\mathrm{Mn}(\mathrm{acac})_{3}\right]$, which has been established to be a good paint drier [11]. The autoxidation activity is also roughly the same for each complex. Thus, based on these facts, it can be concluded that all of the tripodal-ligand manganese complexes are potentially good paint driers. However, although the secondary ligands apparently do not have a major influence on the autoxidation and oligomerisation characteristics of the different complexes, they do have an influence on the solubility of a complex. Complexes with an acac or dpm ligand are much more soluble in apolar solvents, which is of considerable significance for potential alkyd paint driers. Thus, complexes Ia,d, IIa,c, III, and IV are expected to be the 
better candidates for testing as driers in alkyd paint. The complex [Mn(III)(tbpppy)(dpm)] (IIc) is probably the best potential paint drier, due to its excellent solubility, good autoxidation activity, and ease of preparation of the complex.

\section{Conclusion}

Based on the autoxidation and oligomerisation results, it appears that all of the tripodal-ligand manganese complexes that have been studied are potentially good paint driers. As a tentative mechanism for part of the reactivity of the tripodal-ligand complexes, it is proposed that in the direct reaction of a complex with EL, the complex is reduced through the formation of an uncharged secondary ligand. This mechanism is proposed in accordance with the EPR and UV-vis results obtained for the reaction of $[\mathrm{Mn}(\mathrm{pppy})(\mathrm{dpm})]$ with alkyl hydroperoxides, which showed a decrease in the MLCT associated with the dpm ligand and the formation of a coordinated peroxyl radical. Formation of the transient species [Mn(III)(pppy)(OH) $\left.\left({ }^{t} \mathrm{BuOO}^{*}\right)\right]$ is postulated to be responsible for the radical EPR signal. This species is proposed to form from the compound [Mn(pppy)(dpm)] through a reduction and reoxidation step and coordination of the peroxyl radical (Scheme 3). The rather comparable autoxidation results for complexes with different secondary ligands can be explained by assuming that a catalytically active complex with a similar structure for each compound is formed once the secondary ligand has dissociated.

In conclusion, considering parameters such as complex solubility, autoxidation results, and complex preparation, the compound [Mn(III)(tbpppy)(dpm)] is expected to be the best potential alkyd paint drier.

\section{Acknowledgments}

This work was carried out as part of the SENTER/Innovation Oriented Research Program on Heavy Metals (IOP), IZW99241c, sponsored by the Dutch Ministry of Economic Affairs. The crystallography was supported by the Council for the Chemical Sciences of the Netherlands Organisation for Scientific Research (CW-NWO). We thank J.A.P.P. van Dijk for assistance with the SEC measurements and J.A. ErkelensDuijndam for assistance with the MS measurements.

\section{Supplementary material}

Size-exclusion chromatograms for the autoxidation of unpurified EL, catalysed by the complexes Ia, Id, III, IIa, and IId (Fig. S1) and solution UV-vis spectra of complex Id ( $0.25 \mathrm{mmol}$ in $\mathrm{CH}_{3} \mathrm{CN}$ ), after addition of 2 eq of cumyl hydroperoxide (Fig. S2). Crystallographic data (excluding structure factors) for the structural analysis have been deposited with the Cambridge Crystallographic Data Centre, CCDC 652058. Copies of this information may be obtained free of charge from The Director, CCDC, 12 Union Road, Cambridge, CB2 1EZ,
UK (fax: +44 1223336 033; email: deposit@ccdc.cam.ac.uk or www: http://www.ccdc.cam.ac.uk).

Please visit DOI: 10.1016/j.jcat.2007.09.008.

\section{References}

[1] J.R. Bucher, J.R. Hailey, J.R. Roycroft, J.K. Haseman, R.C. Sills, S.L. Grumbein, P.W. Mellick, B.J. Chou, Toxicol. Sci. 49 (1999) 56.

[2] D. Lison, M. De Boeck, V. Verougstraete, M. Kirsch-Volders, Occup. Environ. Med. 58 (2001) 619.

[3] J.H. Bieleman, Additives for Coatings, Wiley-VCH, Weinheim, 2000

[4] R. van Gorkum, E. Bouwman, Coord. Chem. Rev. 249 (2005) 1709.

[5] F. Micciche, J. van Haveren, E. Oostveen, W. Ming, R. van der Linde, Appl. Catal. A Gen. 297 (2006) 174.

[6] Z.O. Oyman, W. Ming, R. van der Linde, Appl. Catal. A Gen. 316 (2007) 191.

[7] Z.O. Oyman, W. Ming, R. van der Linde, R. van Gorkum, E. Bouwman, Polymer 46 (2005) 1731.

[8] R. van Gorkum, E. Bouwman, J. Reedijk, Inorg. Chem. 43 (2004) 2456.

[9] S.T. Warzeska, M. Zonneveld, R. van Gorkum, W.J. Muizebelt, E. Bouwman, J. Reedijk, Prog. Org. Coat. 44 (2002) 243.

[10] J.-Z. Wu, E. Bouwman, J. Reedijk, Prog. Org. Coat. 49 (2004) 103.

[11] R. van Gorkum, E. Bouwman, J. Reedijk, EP1382648 (2004).

[12] A.R. Brash, J. Biol. Chem. 274 (1999) 23679.

[13] C.J. Carrano, M.W. Carrano, K. Sharma, G. Backes, J. Sanders-Loehr, Inorg. Chem. 29 (1990) 1865.

[14] N. Reddig, D. Pursche, B. Krebs, A. Rompel, Inorg. Chim. Acta 357 (2004) 2703

[15] M.U. Triller, D. Pursche, W.Y. Hsieh, V.L. Pecoraro, A. Rompel, B. Krebs, Inorg. Chem. 42 (2003) 6274.

[16] M. Velusamy, M. Palaniandavar, R.S. Gopalan, G.U. Kulkarni, Inorg. Chem. 42 (2003) 8283.

[17] S.P. Yan, X.Y. Pan, L.F. Taylor, J.H. Zhang, C.J. Oconnor, D. Britton, O.P Anderson, L. Que, Inorg. Chim. Acta 243 (1996) 1.

[18] R. van Gorkum, J. Berding, A.M. Mills, H. Kooijman, D.M. Tooke, A.L. Spek, I. Mutikainen, U. Turpeinen, J. Reedijk, E. Bouwman, Eur. J. Inorg. Chem., submitted for publication.

[19] R.E. Boomgaard, H. Schier, E.J.J. Kirchner, R.P. Klaasen, F. Hartl, R.P.C. Van der Leeuw, F.J.A.D. Bakkeren, WO03029371 (2003).

[20] J.Z. Wu, E. Bouwman, J. Reedijk, Prog. Org. Coat. 49 (2004) 103.

[21] R.G. Charles, Inorg. Synth. 7 (1963) 184.

[22] J.G. Wilson, Aust. J. Chem. 43 (1990) 1283.

[23] Y.L. Tong, Y. Yan, E.S.H. Chan, Q.C. Yang, T.C.W. Mak, D.K.P. Ng, J. Chem. Soc. Dalton Trans. (1998) 3057.

[24] G.M. Sheldrick, SHELXS-86: Program for crystal structure determination, University of Göttingen, Göttingen, Germany, 1986.

[25] G.M. Sheldrick, SHELXL-97: Program for crystal structure refinement, University of Göttingen, Göttingen, Germany, 1997.

[26] A.L. Spek, J. Appl. Crystallogr. 36 (2003) 7.

[27] R.W. Brandon, C.S. Elliott, Tetrahedron Lett. (1967) 4375.

[28] A. Tkac, K. Vesely, L. Omelka, J. Phys. Chem. 75 (1971) 2575.

[29] S. Tanase, E. Bouwman, J. Reedijk, Appl. Catal. A Gen. 259 (2004) 101.

[30] W.H. Koppenol, FEBS Lett. 264 (1990) 165.

[31] R.T. Jonas, T.D.P. Stack, J. Am. Chem. Soc. 119 (1997) 8566.

[32] J. Kim, R.G. Harrison, C. Kim, L. Que Jr., J. Am. Chem. Soc. 118 (1996) 4373.

[33] S. Ogo, S. Wada, Y. Watanabe, M. Iwase, A. Wada, M. Harata, K. Jitsukawa, H. Masuda, H. Einaga, Angew. Chem. Int. Ed. 37 (1998) 2102.

[34] G. Roelfes, M. Lubben, K. Chen, R.Y.N. Ho, A. Meetsma, S. Genseberger, R.M. Hermant, R. Hage, S.K. Mandal, V.G. Young Jr., Y. Zang, H. Kooijman, A.L. Spek, L. Que Jr., B.L. Feringa, Inorg. Chem. 38 (1999) 1929.

[35] J. Reedijk, in: G. Wilkinson, R.D. Gillard, J.A. McCleverty (Eds.), Comprehensive Coordination Chemistry, vol. 2, Pergamon Press, Oxford, 1987, p. 74. 